\title{
Development of finasteride polymer microspheres for systemic application in androgenic alopecia
}

\author{
JU HEE KIM ${ }^{1,2^{*}}$, JUNGTAE NA $^{3 *}$, DONG-HO BAK ${ }^{3,4}$, BYUNG CHUL LEE $^{3,4}$, \\ ESTHER LEE ${ }^{3,4}$, MI JI CHOI ${ }^{3,4}$, CHOONG HO RYU ${ }^{2}$, SANGNO LEE $^{2}$, SEOG-KYUN MUN $^{5}$, \\ BYUNG CHEOL PARK ${ }^{6}$, BEOM JOON KIM ${ }^{3,4}$ and HYUN-SHIK LEE ${ }^{1}$
}

\begin{abstract}
${ }^{1}$ KNU-Center for Nonlinear Dynamics, CMRI, School of Life Sciences, BK21 Plus KNU Creative BioResearch Group, College of Natural Science Kyungpook National University, Daegu 41566; ${ }^{2}$ Headquarter, Inventage Lab, Inc., Seongnam, Gyeonggi 13403; ${ }^{3}$ Department of Dermatology, College of Medicine, Chung-Ang University; ${ }^{4}$ Department of Medicine, Graduate School, Chung-Ang University; ${ }^{5}$ Department of Otorhinolaryngology-Head and Neck Surgery, College of Medicine, Chung-Ang University, Seoul 06973; ${ }^{6}$ Department of Dermatology,

Dankook Medical College, Cheonan, Chungcheongnam 31116, Republic of Korea
\end{abstract}

Received October 8, 2018; Accepted March 27, 2019

DOI: $10.3892 / \mathrm{ijmm} .2019 .4149$

\begin{abstract}
The use of finasteride for alleviating hair loss has been investigated, and it has been applied as an oral dose medication. However, due to the inconvenience of daily drug administration over long period of time, novel controllable finasteride delivery has been actively investigated. As a novel method of finasteride delivery, the development of finasteride-loaded microspheres for subcutaneous administration is becoming increasingly pharmaceutically important. Therefore, the present study aimed to use finasteride-loaded microspheres in a controlled manner in an attempt to overcome the limitations of the oral administration of finasteride and to cause fewer adverse effects. Finasteride-loaded microspheres containing poly(lactic-co-glycolic acid) and finasteride at a ratio of 4:1 were prepared, and a testosterone-induced androgenic alopecia mouse model was used. Following observation for 10 weeks, the percentage hair growth was $86.7 \%$ (total hair growth $60 \%$, partial hair growth $26.7 \%$ ) in the orally-applied finasteride-treated group as a positive
\end{abstract}

Correspondence to: Dr Beom Joon Kim, Department of Dermatology, College of Medicine, Chung-Ang University, 102 Heukseok-ro, Dongjak-gu, Seoul 06973, Republic of Korea E-mail: beomjoon74@gmail.com

Dr Hyun-Shik Lee, KNU-Center for Nonlinear Dynamics, CMRI, School of Life Sciences, BK21 Plus KNU Creative BioResearch Group, College of Natural Science Kyungpook National University, 80 Daehak-ro, Buk-gu, Daegu 41566, Republic of Korea

E-mail: leeh@knu.ac.kr

*Contributed equally

Key words: finasteride, microsphere, testosterone, dihydrotestosterone, apoptosis control, and $93.3 \%$ (total hair growth $60 \%$, partial hair growth $33.3 \%$ ) in the finasteride-loaded microspheres-treated group. Serum dihydrotestosterone levels began to decrease at week 6 in the orally-applied finasteride- and finasteride-loaded microsphere-treated groups. In addition, the finasteride-loaded microspheres-treated group exhibited similar follicular number, follicular length, anagen/telogen ratio and hair bulb diameter values to those of the orally-applied finasteride-treated group. Furthermore, the finasteride-loaded microspheres increased the activities of phosphoinositide 3-kinase/protein kinase B and Wnt/ $\beta$-catenin in relation to hair follicle cell growth signaling in mouse skin, and suppressed the apoptosis of hair follicle cells by reducing the expression of transforming growth factor- $\beta 2$ and caspase- 3 , which are indicators of apoptosis. In conclusion, the administration of a single injection of finasteride-loaded microspheres was effective in treating testosterone-induced alopecia. Furthermore, it led to equivalent hair growth effects when compared with orally-applied finasteride, thus revealing the possibility of effective treatment via different routes of administration.

\section{Introduction}

Androgenic alopecia (AGA) is a genetic disease that affects men and is associated with the androgen steroid hormone. It is characterized by patterned hair loss from the scalp, and is recognized as a condition affecting physical and mental wellbeing $(1,2)$. The characteristic symptoms of AGA include a gradual decrease in terminal hair density and a simultaneous increase in the density of short and unpigmented hair. This effect contributes to the miniaturization of hair follicles and the reduction of hair diameter (3). With regard to the etiology of AGA, the conversion of testosterone to dihydrotestosterone (DHT) is catalyzed by $5 \alpha$-reductase, and DHT then binds to the androgen receptor of the dermal papilla cells (DPCs) in the hair follicles to suppress the proliferation of DPCs and sustain the telogen phase, thereby inhibiting the formation of new hair (4). 
Finasteride is a $5 \alpha$-reductase, acting as an antiandrogen in the prostate gland and scalp $(5,6)$. Finasteride was originally developed to treat benign prostatic hyperplasia; however, as hirsutism was observed as a side effect, it was developed as a hair growth solution. Consequently, finasteride alleviates AGA by suppressing the activity of $5 \alpha$-reductase and reducing DHT levels (7). Studies have reported decreased DHT levels in the serum and scalp following oral administration of finasteride $(8,9)$. A clinical trial reported that 1-mg daily dosing of finasteride administered to men with AGA for 48 weeks delayed the progression of hair loss and increased hair growth (10). Other clinical trials in which 1,879 men were monitored for 5 years demonstrated that oral finasteride treatment reduced hair loss $(11,12)$, and that the daily administration of $1 \mathrm{mg}$ oral finasteride increased hair count and improved hair appearance (13). However, to maintain these therapeutic effects, oral finasteride should be administered daily for a long time, and the inconvenience of daily drug administration has been highlighted as a disadvantage. Therefore, studies have been conducted to deliver finasteride in a controlled manner causing fewer adverse effects. The polycarbonate, poly(propylene carbonate maleate) microspheres loaded with finasteride have been shown to exhibit continuous drug release up to 5-6 weeks in vitro (14). Furthermore, the topical application of chitosan-decorated polystyrene-b-poly(acrylic acid) polymersomes with finasteride improves the drug penetration and accumulation in the skin layer (15).

Polymer microspheres are widely used in the pharmaceutical field due to their reduced toxicity, improved efficacy, and patient convenience and compliance (16). Aliphatic polyester polymers, including poly(L-lactide), poly(glycoside) and poly( $\varepsilon$-caprolactone), represent a family of biodegradable materials (17-19). In particular, biodegradable polymers, such as poly(lactic-co-glycolic acid) (PLGA), have been widely used due to their various properties including safety, biodegradability, compatibility with different hydrophilic and hydrophobic types of drugs, sustained drug release and targeting of specific organs (20). PLGA particles can generally be prepared via phase separation, spray drying and solvent extraction-evaporation processes. The sustained or controlled release of the drug from these particles is also possible, depending on the rate of hydrolysis of the polymer (21). The chemical structure of PLGA provides various physicochemical properties depending on the ratios of lactic and glycolic acids. Selecting the appropriate type of PLGA is important in ensuring successful drug delivery (22). The use of extended-release products also offers potential benefits, including sustained drug levels in the blood, fewer adverse effects and improved patient compliance. The preparation of controlled-release forms is therefore important.

In the present study, finasteride-loaded microspheres were used to enable the controlled release of finasteride from PLGA microspheres in mice. The study aim was to confirm the efficacy of a single injection of finasteride-loaded microspheres on the alleviation of hair loss through an in vivo experiment, by comparing its effects with those of daily orally-applied finasteride treatment in mice in order to assess in the future the possibility of administration in patients with alopecia.

\section{Materials and methods}

Preparation of finasteride-loaded microspheres. To produce finasteride-loaded microspheres, an Inventage Lab Precision Particle Fabrication (IVL-PPF) method based on micro-electromechanical systems was used. Briefly, finasteride (Aurobindo Pharma, Ltd., Hyderabad, India) was dispersed in $20 \mathrm{ml}$ dichloromethane (DCM; J.T. Baker, Phillipsburg, NJ, USA) containing the PLGA 7502A (PURAC Asia Pacific Pte. Ltd., Singapore) biodegradable polymer for organic phase solutions, and the surfactant polyvinyl alcohol (PVA; Merck KGaA, Darmstadt, Germany) was dissolved in purified water at a concentration of $0.25 \%$ to prepare a $250-\mathrm{ml}$ water phase solution. The organic and water phase solutions were introduced into the microchannels of the IVL-PPF device and the finasteride-loaded microspheres were manufactured and collected in a collecting bath. To obtain the pure finasteride-loaded microspheres, stirring was continued for $3 \mathrm{~h}$ at $250 \mathrm{rpm}$ on a magnetic stirrer at temperatures increasing from 17 to $25^{\circ} \mathrm{C}$ until the DCM had completely evaporated. This was followed by washing in distilled water, freezing and lyophilizing using a freeze-drier.

Characterization of finasteride-loaded microspheres. The prepared microspheres were characterized according to particle morphology, size, drug content and microsphere production yield. The microspheres were visualized using a scanning electron microscope (SEM; SNE-3000MS, SEC Co., Ltd., Suwon, Korea) to examine the morphology and the particle surface structure. A laser-light particle size analyzer (S3550; Microtrac, Inc., Montgomeryville, PA, USA) was used for particle size analysis. With regard to drug content, $0.1 \mathrm{mg} / \mathrm{ml}$ of finasteride test solution was prepared by dissolving $50 \mathrm{mg}$ microspheres in acetonitrile (Sigma-Aldrich; Merck KGaA) to obtain $100 \mathrm{ml}$ solution, which was analyzed via high-performance liquid chromatography (HPLC; ULTIMATE-3000, Thermo Fisher Scientific, Inc., Waltham, MA, USA).

Animals. Male, 5-week-old C57BL/6 mice were supplied by RaonBio, Inc. (Yongin, Korea). Solid feed (antibiotic-free) and water were sufficiently supplied until the day of the experiment, and the animals that were used for the experiment were acclimatized for 1 week to a temperature of $23 \pm 2^{\circ} \mathrm{C}$, humidity of $55 \pm 10 \%$ and 12 -h light/dark cycles. All experimental procedures were conducted based on the principles of laboratory animal care of the National Institute of Health (Bethesda, MA, USA) and were approved by the Ethics Committee for Laboratory Animals at Chung-Ang University (Seoul, Korea; no. 201800078).

Androgenic alopecia mouse model. Treatment with reagents was performed as described previously with modifications (23). The hair on the back of the male mice was removed with an electric clipper. A total of 60 mice were randomly divided into four groups of 15 mice. All mice, with the exception of those in the control group, were subcutaneously injected with $0.1 \mathrm{ml}$ of $5 \mathrm{mg} / \mathrm{ml}$ testosterone propionate (TP; Tokyo Chemical Industry, Tokyo, Japan) once daily for 8 weeks. The mice in the microspheres- and finasteride-loaded microspheres-treated $(15 \mathrm{mg} / \mathrm{ml})$ groups were subcutaneously 
injected with $0.1 \mathrm{ml}$ on the first day of the experiment, and mice in the orally-applied finasteride-treated group $(0.1 \mathrm{mg} / \mathrm{ml})$ were orally administered with $0.1 \mathrm{ml}$ finasteride once daily for 56 days. Mice in the control group were not treated with TP or finasteride. After 8 weeks, hair growth was observed for a period of 2 weeks. The differences in hair growth in each group were evaluated visually and recorded weekly through image capture (Canon 3000D; Canon, Inc., Tokyo, Japan). The effect of preventing androgenic alopecia was assessed by measuring changes in the color of the mouse back skin, which indicates hair cycle transitions. Mice with completely hair-covered backs were counted as 'total' and partially hairy mice as 'partial'. Histological changes, including the number, length, anagen/telogen ratio and diameter of hair follicles, were also evaluated by hematoxylin and eosin (H\&E) staining. The experiment was performed over a total of 10 weeks. After 9 and 10 weeks, the mice were sacrificed, and their skins were harvested.

RNA extraction and reverse transcription-quantitative polymerase chain reaction $(R T-q P C R)$ analysis. Total RNA was extracted from isolated skin tissues using Tri-RNA reagent (Favorgen Biotech Corporation, Ping-Tung, Taiwan). Single-stranded cDNA was synthesized from whole RNA templates using Prime Script ${ }^{\mathrm{TM}}$ RT Master mix (Takara Bio, Inc., Tokyo, Japan). RT was performed after gently mixing the reaction solution; the solution was then incubated at $37^{\circ} \mathrm{C}$ for $15 \mathrm{~min}$ and $85^{\circ} \mathrm{C}$ for $5 \mathrm{sec}$; cDNA was maintained at $4^{\circ} \mathrm{C}$ until qPCR. The resulting cDNA was subjected to qPCR using qPCR 2X PreMIX SYBR (Enzynomics, Seoul, Korea) with the CFX-96 system (Bio-Rad Laboratories, Inc., Hercules, CA, USA). The PCR used to amplify all genes was performed over 40 cycles $\left(95^{\circ} \mathrm{C}\right.$ for $10 \mathrm{sec}, 60^{\circ} \mathrm{C}$ for $15 \mathrm{sec}$ and $72^{\circ} \mathrm{C}$ for $30 \mathrm{sec}$ ), following denaturation at $95^{\circ} \mathrm{C}$ for $10 \mathrm{~min}$. The expression levels were calculated from the quantification cycle $(\mathrm{Cq})$ value using the $\Delta \mathrm{Cq}$ quantification method (24), and expression was normalized to that of $60 \mathrm{~S}$ acidic ribosomal protein P0 (Rplp0). Amplification was performed using the following primers: Mouse Wnt3a forward, 5'-CTCGCTGGCTACCCA ATTTG-3' and reverse, 5'-CTTCACACCTTCTGCTAC GCT-3'; mouse dickkopf WNT signaling pathway inhibitor 1 (Dkkl) forward, 5'-CTCATCAATTCCAACGCGATCA-3' and reverse, 5'-GCCCTCATAGAGAACTCCCG-3'; mouse alkaline phosphatase $(A l p l)$ forward, 5'-CCAACTCTTTTG TGCCAGAGA-3' and reverse, 5'-GGCTACATTGGTGTT GAGCTTTT-3'; and mouse Rplp0 forward, 5'-AGATTCGGG ATATGCTGTTGGC-3' and reverse, 5'-TCGGGTCCTAGA CCAGTGTTC-3'.

Immunoblot assay. The isolated skin tissues were dissolved in PRO-PREP (Intron Biotechnology, Inc., Seongnam, Korea) and centrifuged at $14,000 \mathrm{x}$ g for $20 \mathrm{~min}$ at $4^{\circ} \mathrm{C}$. Protein content in the supernatants was quantified using a BCA kit (Thermo Fisher Scientific, Inc.). The proteins in the supernatant (total protein content, $30 \mu \mathrm{g}$ ) were heated for $5 \mathrm{~min}$ at $100^{\circ} \mathrm{C}$. Each sample was subjected to $12 \%$ sodium dodecyl sulfate-polyacrylamide gel electrophoresis, and the separated proteins were transferred onto a polyvinylidene fluoride (PVDF) membrane (EMD Millipore, Billerica, MA, USA). The PVDF membrane was blocked using 5\% skim milk for $1 \mathrm{~h}$ at room temperature and incubated with anti-transforming growth factor (TGF)- $\beta 2$ (1:1,000, cat. no. sc-90; Santa Cruz Biotechnology, Inc., Santa Cruz, CA, USA), caspase-3 (1:2,500, cat. no. 9662), poly (ADP-ribose) polymerase (PARP; 1:2,500, cat. no. 9532S; both Cell Signaling Technology Inc., Beverly, MA, USA), B-cell lymphoma 2 (Bcl-2; 1:1,000, cat. no. sc-492), Bcl-2-associated X protein (Bax; 1:1,000, cat. no. sc-7480; both Santa Cruz Biotechnology, Inc.), Wnt3a (1:2,500, cat. no. ab28472; Abcam, Cambridge, UK), phospho (p)-glycogen synthase kinase $3 \beta$ (GSK3 $\beta ; 1: 2,500$, cat. no. 5558), GSK3 $\beta$ (1:2,500, cat. no. 9315), p- $\beta$-catenin $(1: 2,500$, cat. no. 4176S), $\beta$-catenin $(1: 2,500$, cat. no. 8814S; all Cell Signaling Technology, Inc.), and $\beta$-actin (1:1,000, cat. no. sc-47778; Santa Cruz Biotechnology, Inc.) antibodies at $4^{\circ} \mathrm{C}$ for $12 \mathrm{~h}$. After washing with Tris-buffered saline with Tween ${ }^{\circledR}-20$ (TBST), horseradish peroxidase (HRP)-conjugated anti-mouse (1:10,000; cat. no. PI-2000) or anti-rabbit (1:10,000; cat. no. PI-1000) secondary antibodies (Vector Laboratories, Inc., Burlingame, CA, USA) specific to the primary antibody was added and incubated at room temperature for $1 \mathrm{~h}$. After washing, the membranes were color-developed using electrochemiluminescence solution (EMD Millipore) and assessed using a ChemiDoc ${ }^{\mathrm{TM}}$ XRS+ system (Bio-Rad Laboratories, Inc.).

Histological examination. The tissue slides were prepared according to methods described previously (25), and the tissues were sliced into $6-\mu \mathrm{m}$ sections. Deparaffinized skin sections were stained with H\&E staining (hematoxylin for $5 \mathrm{~min}$ and eosin for $30 \mathrm{sec}$ at room temperature). Following staining, the tissues were dehydrated, sealed and examined using an optical microscope (DM750; Leica Microsystems $\mathrm{GmbH}$, Wetzlar, Germany). The follicular length and diameter were evaluated using the longitudinal section parallel to the direction of hair growth. The follicular number, anagen follicles (A), and telogen follicles (T) were measured, and the $\mathrm{A} / \mathrm{T}$ ratio was calculated by analyzing the transverse section.

Immunohistochemistry was performed using the UltraVision LP Large Volume Detection System HRP Polymer kit (Thermo Fisher Scientific, Inc.). Anti- $\beta$-catenin (1:500, cat. no. 8814S; Cell Signaling Technology, Inc.) and anti-TGF- $\beta 2$ (1:500, cat. no. sc-90; Santa Cruz Biotechnology, Inc.) primary antibodies were used for incubation at $4^{\circ} \mathrm{C}$ for $18 \mathrm{~h}$ in a moist chamber. After washing of the slides, a primary antibody enhancer was added for $10 \mathrm{~min}$, and a HRP polymer solution was added for further incubation at room temperature for $15 \mathrm{~min}$. After washing, the slides were color-developed using 3,3'-diaminobenzidine for 10-30 sec and were dehydrated and sealed for observation following contrast staining with Mayer's hematoxylin. After staining, tissues were observed via optical microscopy (DM750; Leica Microsystems $\mathrm{GmbH}$ ).

Terminal deoxynucleotidyl transferase dUTP nick end labeling (TUNEL) staining. To evaluate the apoptosis of hair follicles, TUNEL staining was performed using a DeadEnd ${ }^{\mathrm{TM}}$ Fluorometric TUNEL system (Promega Corporation, Madison, WI, USA). The tissue slides were deparaffinized and rehydrated, and the tissue sections were fixed in $4 \%$ methanol-free formaldehyde solution in PBS for $15 \mathrm{~min}$ 
A
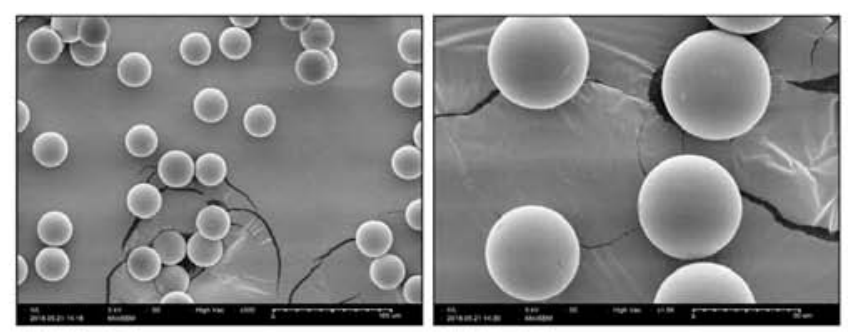

B

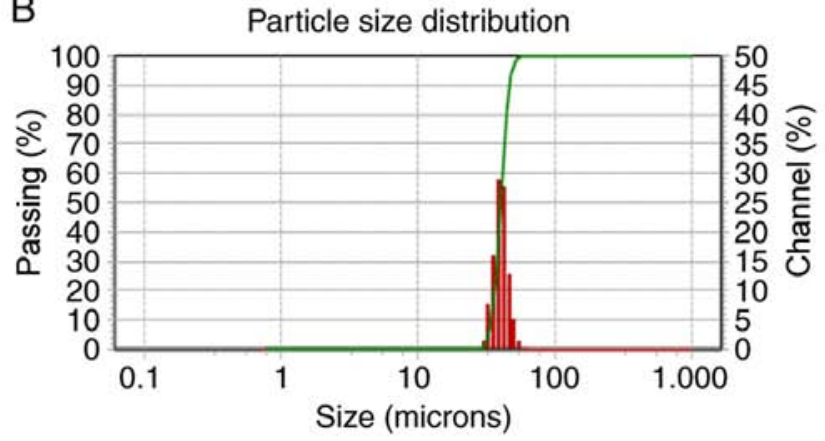

UV_VIS_1

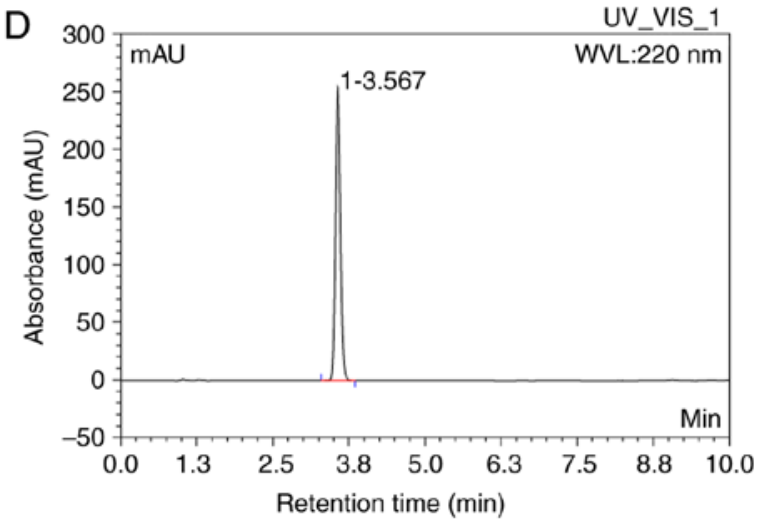

UV_VIS_1
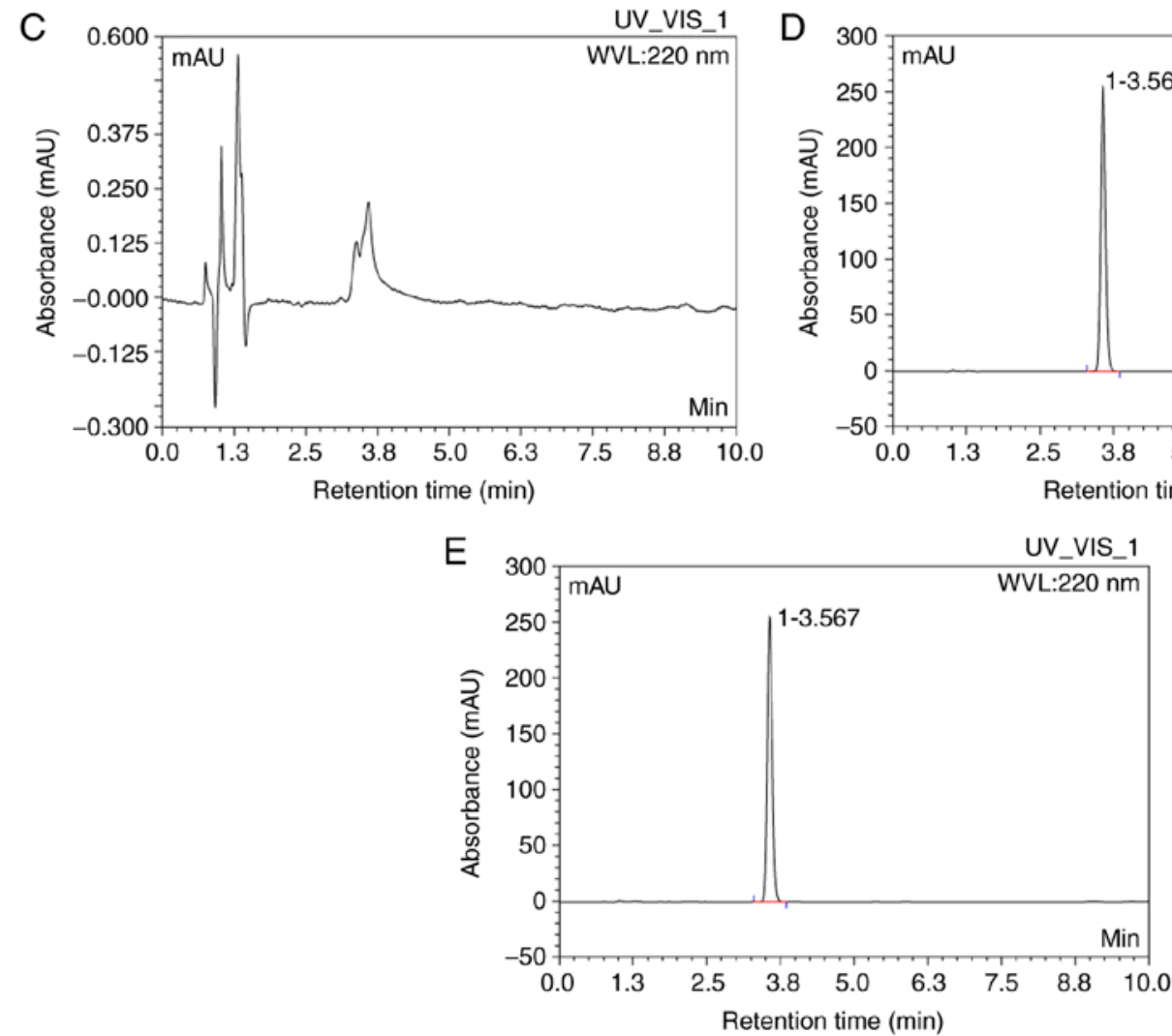

Figure 1. Characterization of finasteride-loaded microspheres. (A) Scanning electron microscopy images of selected finasteride-loaded microspheres. Finasteride-loaded microspheres were smooth and spherical with a size of 30-50 $\mu \mathrm{m}$. (B) Finasteride-loaded microsphere particle size distribution by volume was evaluated. The particle size distribution width was $9.29 \mu \mathrm{m}$ and the median diameter was $40 \mu \mathrm{m}$. The green line indicates cumulative volume (\%) of particle size. Representative images of high-performance liquid chromatography peaks of the (C) placebo microspheres, (D) finasteride standard and (E) finasteride-loaded microspheres. The finasteride content in the finasteride-loaded microspheres was $99.2 \%$.

at room temperature. After washing twice in PBS, each slide was incubated with $20 \mu \mathrm{g} / \mathrm{ml}$ Proteinase K for $10 \mathrm{~min}$ at room temperature. The tissue sections were then fixed in $4 \%$ methanol-free formaldehyde for $5 \mathrm{~min}$ at room temperature. After washing in PBS, the slides were incubated with a nucleotide mix and recombinant terminal deoxynucleotidyl transferase for $1 \mathrm{~h}$ at $37^{\circ} \mathrm{C}$, avoiding exposure to light. The reaction was terminated by the addition of a stop solution for $15 \mathrm{~min}$ at room temperature. After washing in PBS, the tissues were mounted in VECTASHEILD mounting medium with 4',6-diamidino-2-phenylindole (DAPI; cat. no. H-1200; Vector Laboratories, Inc.), and green fluorescence of the dead cells (fluorescein-12-dUTP) was detected. Fluorescence images were captured via confocal microscopy (LSM 700; Zeiss GmbH, Jena, Germany).
Measurement of total serum testosterone and DHT. The blood samples $(1.5 \mathrm{ml})$ collected from mice were centrifuged at $4^{\circ} \mathrm{C}$ and $1,000 \mathrm{xg}$ for $30 \mathrm{~min}$. Following centrifugation, the supernatant was stored at $-70^{\circ} \mathrm{C}$ until further analysis. Serum testosterone (cat. no. CSB-E05101m) and DHT (cat. no. CSB-E07880m) were measured via enzyme linked immunosorbent assays (ELISA; Cusabio, Wuhan, China). Each sample (50 $\mu \mathrm{l}$ each in duplicate) was placed in a 96-well plate, and $50 \mu 1$ of HRP-conjugate and $50 \mu \mathrm{l}$ of antibodies (testosterone or DHT) were added to each well, followed by incubation for $1 \mathrm{~h}$ at $37^{\circ} \mathrm{C}$. After washing three times with wash buffer, $50 \mu \mathrm{l}$ of substrate A and $50 \mu \mathrm{l}$ of substrate B were added and incubated for $15 \mathrm{~min}$ at $37^{\circ} \mathrm{C}$ for color development. The reaction was then terminated by the addition of $50 \mu \mathrm{l}$ stop solution, and the absorbance was measured at $450 \mathrm{~nm}$ using a Spectra Max i3x 
A

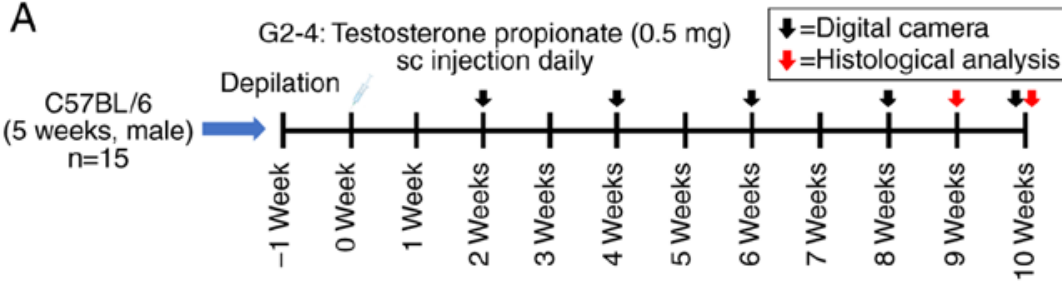

G2: Microspheres $(0.1 \mathrm{ml}) \mathrm{sc}$ injection once

G3: Orally-applied finasteride $(0.01 \mathrm{mg})$ daily

G4: Finasteride-loaded microspheres $(1.5 \mathrm{mg}) \mathrm{sc}$ injection once

B

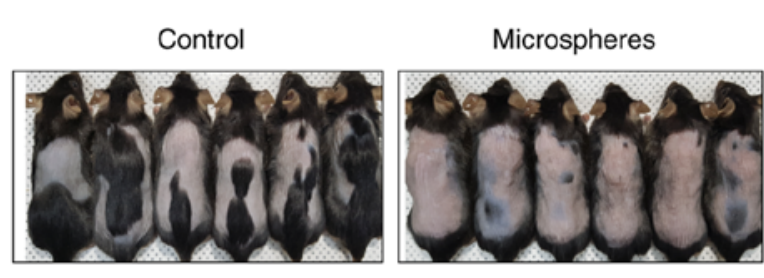

TP
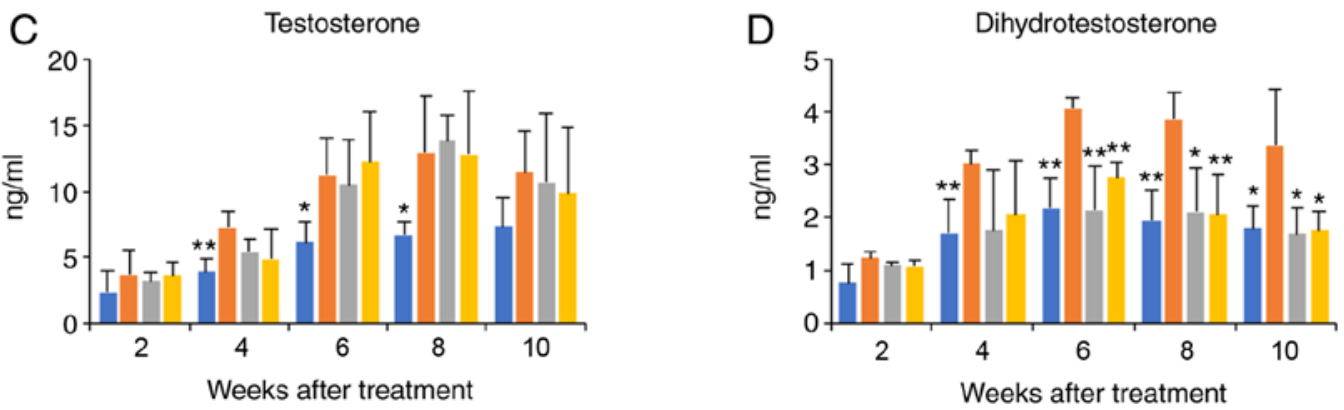

- Control

$=\mathrm{TP}+$ microspheres

$=$ TP+orally-applied

TP+FNS-loaded

microspheres

Figure 2. FNS-loaded microspheres effectively prevent $5 \alpha$-reductase activity in a testosterone-induced androgenic alopecia mouse model. (A) Schematic diagram of the study protocol. The mice were administered with the test compounds orally or subcutaneously for 8 weeks. (B) Images of the dorsal skin at 8 weeks. Individual data were obtained using enzyme-linked immunosorbent assays for (C) testosterone and (D) DHT in serum. The DHT levels decreased 4 weeks after orally-applied FNS and FNS-loaded microspheres administration. All data are presented as the mean \pm standard error of the mean from three independent experiments. ${ }^{*} \mathrm{P}<0.05$ and ${ }^{* *} \mathrm{P}<0.01$, vs. microspheres-treated group. FNS, finasteride; TP, testosterone propionate; DHT, dihydrotestosterone.

Multi-Mode detection platform (Molecular Devices, LLC, Sunnyvale, CA, USA).

Statistical analysis. All statistical analyses were performed using the Statistical Package for the Social Sciences (IBM SPSS statistics version 25, IBM Corp., Armonk, NY, USA). The experiment results are expressed as the mean \pm standard error of the mean, and statistical significance was evaluated via one-way or two-way analysis of variance for the levels of serum testosterone and DHT. Tukey's honest significance test was performed post hoc, and $\mathrm{P}<0.05$ was considered to indicate a statistically significant difference.

\section{Results}

Characterization of finasteride-loaded microspheres. The morphology and size of microspheres containing finasteride were analyzed. The SEM analysis of the prepared finasteride-loaded microspheres revealed smooth and perfectly spherical microspheres and the absence of collapsed spheres (Fig. 1A). Finasteride was encapsulated in the PLGA polymer and homogeneously prepared, and the micrographs did not exhibit any pores on the microspheres. The diameter of the prepared finasteride-loaded microspheres was $\sim 30-50 \mu \mathrm{m}$ as determined via SEM analysis. The particle size and distribution of the finasteride-loaded microspheres were measured using a laser diffraction particle size analyzer. The particle diameter ranged between 30 and $50 \mu \mathrm{m}$ with a median diameter of $40 \mu \mathrm{m}$ and a size distribution width of $9.29 \mu \mathrm{m}$. That indicates the majority of particles were similar in size, close to the median diameter, as shown in Fig. 1B; a narrower size distribution of particles generally improves drug release characteristics.

The contents of the prepared finasteride-loaded microspheres were confirmed via HPLC analysis, and the unique finasteride standard peaks (retention time, $3.57 \mathrm{~min}$; peak area, 24.40) and the drug peaks (retention time, $3.52 \mathrm{~min}$; peak area, 24.20) were examined (Fig. 1C-E). The drug content measured in the microspheres was $99.2 \%$.

Subcutaneous administration of finasteride-loaded microspheres induces hair follicle growth via the inhibition of $5 \alpha$-reductase in a testosterone-induced AGA mouse model. To investigate the effect of finasteride-loaded microspheres on 

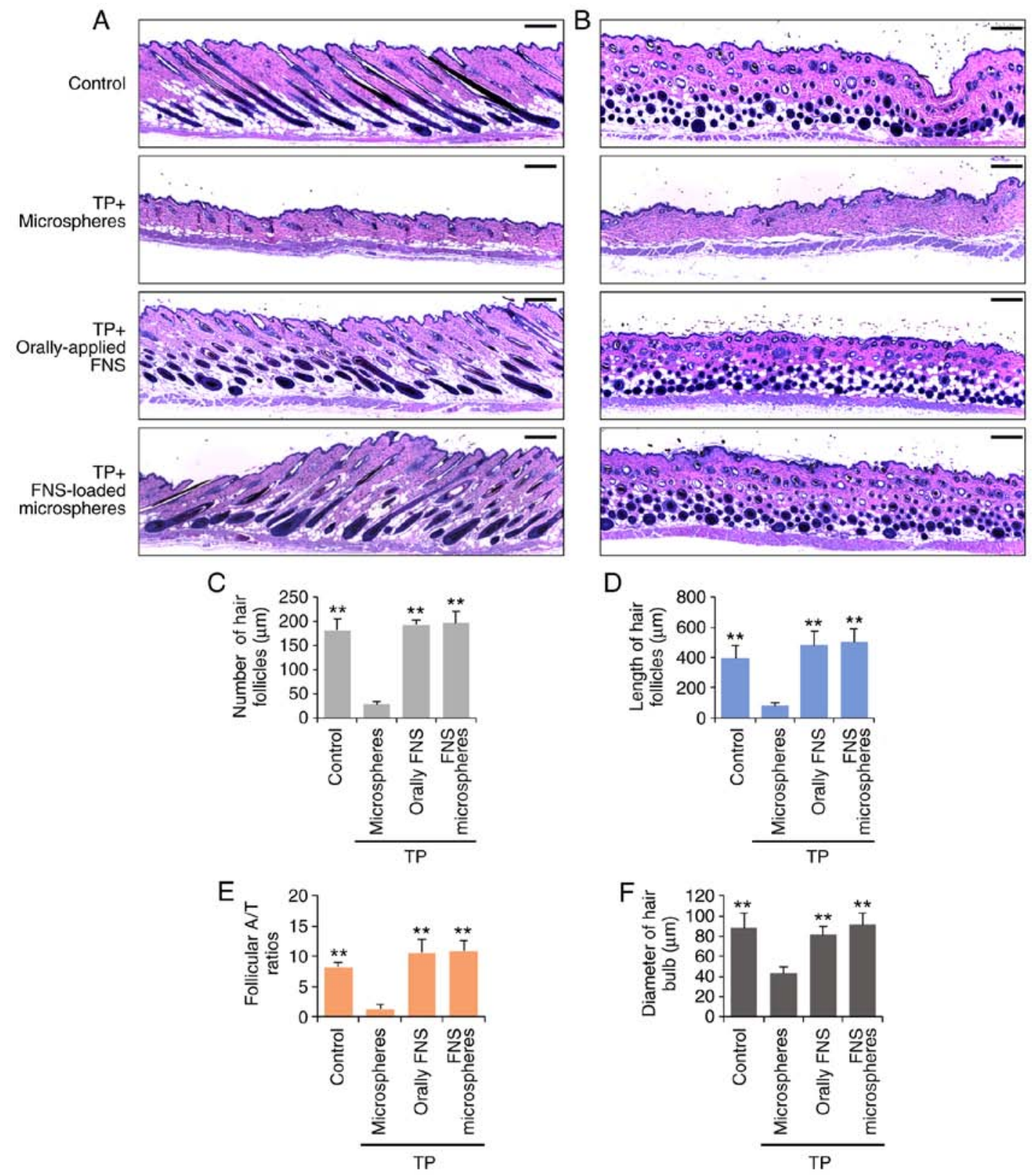

Figure 3. FNS-loaded microspheres reduce testosterone-induced catagen in C57BL/6 mice. Mice were sacrificed and skin biopsies were obtained 9 weeks after the start of treatment. (A) Longitudinal sections and (B) transverse sections of dorsal skin tissues were stained with hematoxylin and eosin. Scale bar, $200 \mu \mathrm{m}$. (C) Follicular number, (D) follicular length, (E) A/T ratio and (F) follicular diameters were assessed. The sections were observed under a light microscope and images were captured. All data are presented as the mean \pm standard error of the mean from three independent experiments. ${ }^{* *} \mathrm{P}<0.01$, vs. microspheres-treated group. TP, testosterone propionate; FNS, finasteride; A/T ratio, anagen and telogen ratio.

AGA in the murine model, hair loss was induced in the dorsal skin of C57BL/6 mice via testosterone treatment (Fig. 2A). In the control mice, hair growth was observed from week 4 and in $80 \%$ of the mice (total hair growth, $46.6 \%$; partial hair growth, 33.3\%). However, hair began to grow from week 6 in the orally-applied finasteride and the finasteride-loaded microspheres treatment groups. At week 10, hair growth was observed in $86.7 \%$ of mice (total, 60\%; partial, 26.7\%) in the orally-applied finasteride-treated group, and $93.3 \%$ of mice (total, 60\%; partial, $33.3 \%$ ) in the finasteride-loaded microspheres-treated group. In the microspheres-treated group, hair grew in $33.3 \%$ of the mice (total, 6.7\%; partial, 26.7\%) (Figs. 2B and S1).

The levels of serum testosterone and DHT in the TP-induced mice were significantly higher than those in the control group in the first 8 weeks (Fig. 2C and D). However, the DHT levels were significantly lower in the orally-applied finasteride- and finasteride-loaded microspheres-treated groups than in the microspheres-treated group after 6 weeks. There was no difference between the orally-applied finasteride- and finasteride-loaded microspheres-treated groups. These results suggest that the $5 \alpha$-reductase inhibitory effect of the finasteride-loaded microspheres may last for $\sim 4-8$ weeks following a single injection, and that treatment with finasteride-loaded microspheres exerts similar effects to daily orally-applied finasteride.

Finasteride-loaded microspheres reduce testosterone-induced catagen in C57BL/6 AGA mice. The tissues observed in the longitudinal and transverse sections revealed that the hair 
A

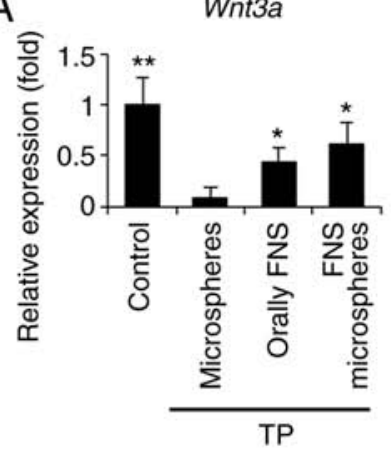

DKK1

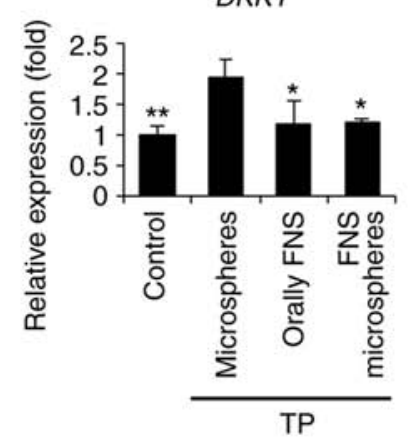

B

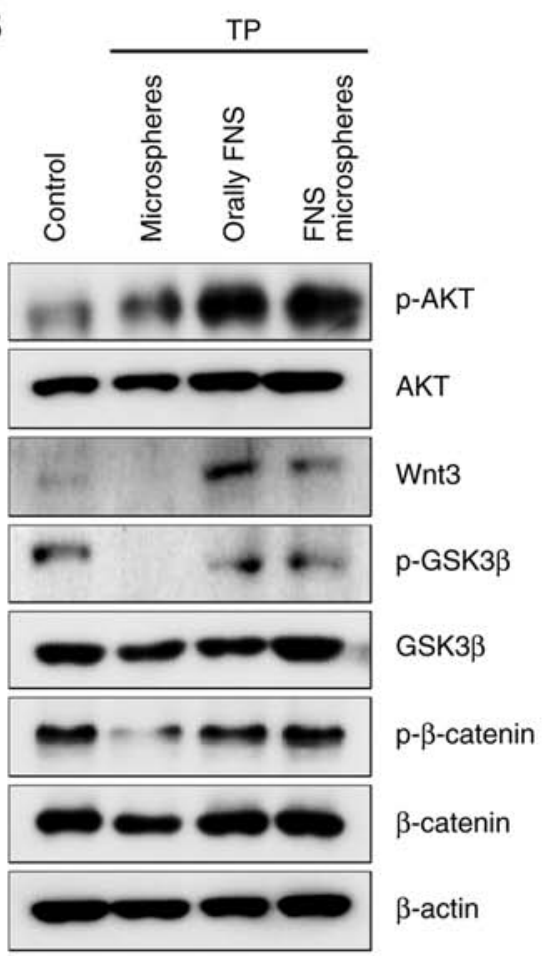

C

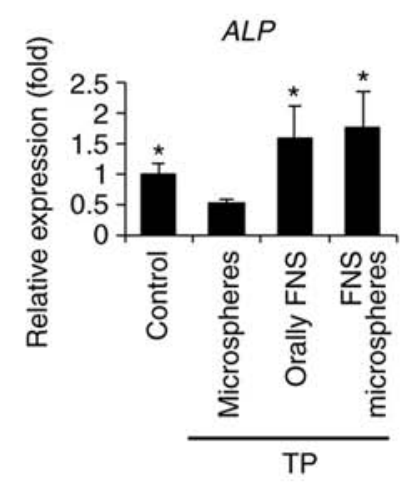

TP

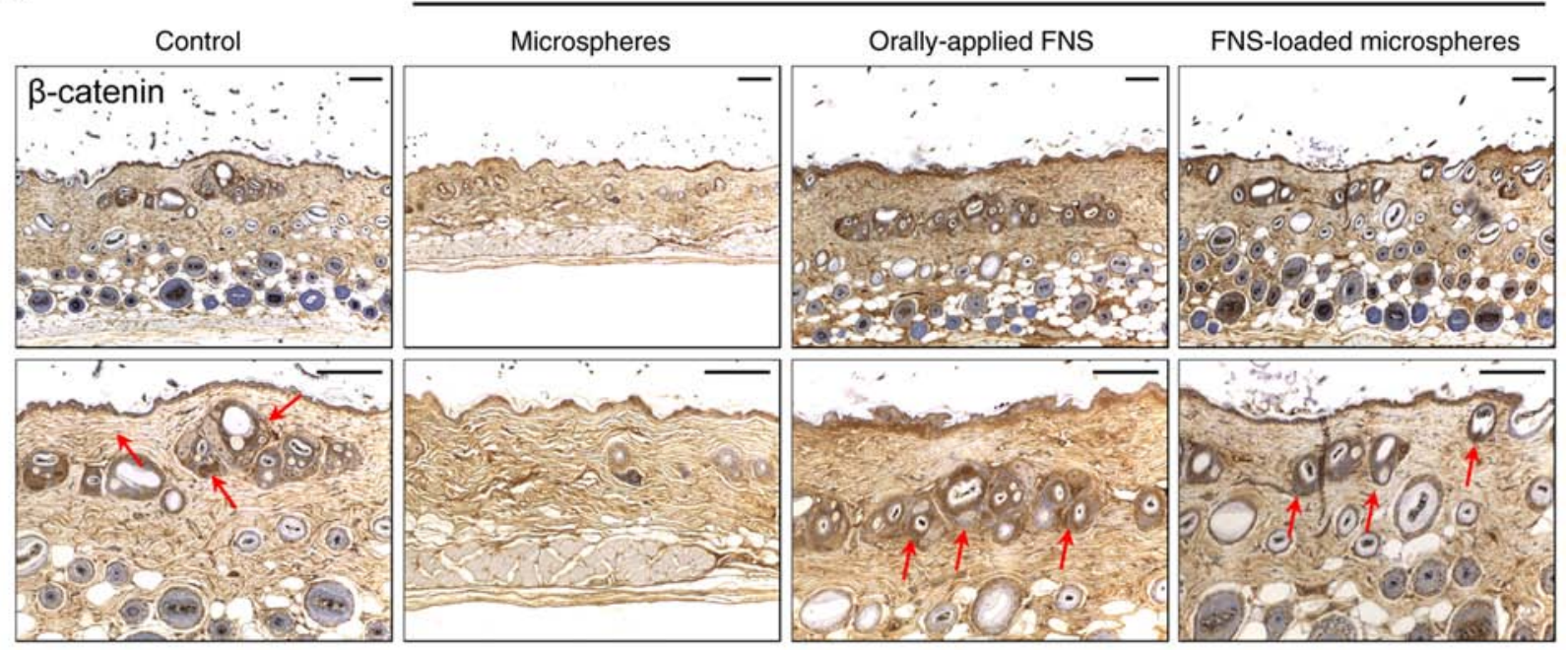

Figure 4. FNS-loaded microspheres efficiently induce entry into the anagen phase in a testosterone-induced androgenic alopecia mouse model. Mice were sacrificed and skin biopsies were obtained 9 weeks after the start of treatment. (A) Following treatment with testosterone and orally-applied FNS or FNS-loaded microspheres, Wnt $3 a, D k k l$ and Alp transcripts were detected via reverse transcription-quantitative polymerase chain reaction analysis. (B) Dorsal skin lysates were immunoblotted using anti-p-Akt, anti-Wnt3a, anti-p-GSK-3 $\beta$, anti-p- $\beta$-catenin and anti- $\beta$-actin antibodies. (C) Comparison of histological images ( $\beta$-catenin indicated by red arrows). Scale bar, $100 \mu \mathrm{m}$. All data are presented as the mean \pm standard error of the mean from three independent experiments. ${ }^{*} \mathrm{P}<0.05$ and $^{* *} \mathrm{P}<0.01$, vs. microspheres-treated group. TP, testosterone propionate; FNS, finasteride; DKK1, dickkopf WNT signaling pathway inhibitor 1; ALP, alkaline phosphatase; AKT, protein kinase B; GSK-3 $\beta$, glycogen synthase kinase $3 \beta ;$ p-, phosphorylated.

follicle tissue was in the anagen phase (Figs. 3A and B and S2). The miniaturization of hair follicles was observed in the skin sections of mice treated with TP and the microspheres, however, the number and length of hair follicles was markedly increased in the orally-applied finasteride- and finasteride-loaded microspheres-treated groups (Figs. 3C and D, S2C and D). At weeks 9 and 10, the orally-applied finasteride- and finasteride-loaded microspheres-treated mice exhibited significantly higher numbers of anagen hair follicles $(\mathrm{A} / \mathrm{T}$ ratio), and the hair bulb diameters were larger than those in the microspheres-treated mice (Figs. 3C and S2C). In addition, the expression of Wnt3a increased, the protein kinase B (Akt)/GSK-3 $\beta / \beta$-catenin signaling pathway was activated and the expression of $\beta$-catenin was increased in the newly developed hair follicles (Fig. 4A-C). Taken together, these results indicate that a single injection of finasteride-loaded microspheres results in marked hair growth-promoting activity and catagen-induction preventative effects, similar to those of orally-applied finasteride.

Finasteride-loaded microspheres suppress hair follicle apoptosis in a testosterone-induced AGA mouse model. DHT 
A

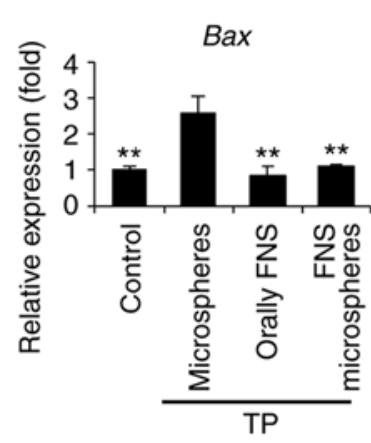

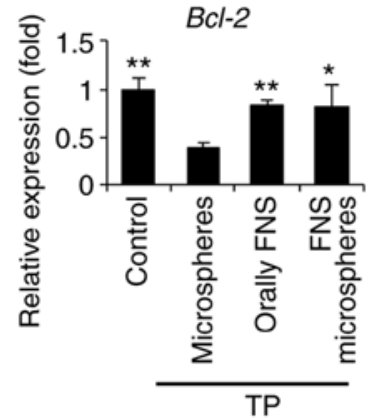

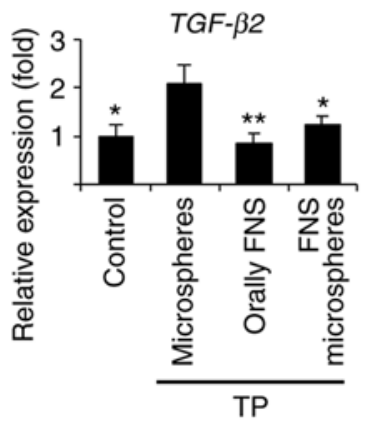

B

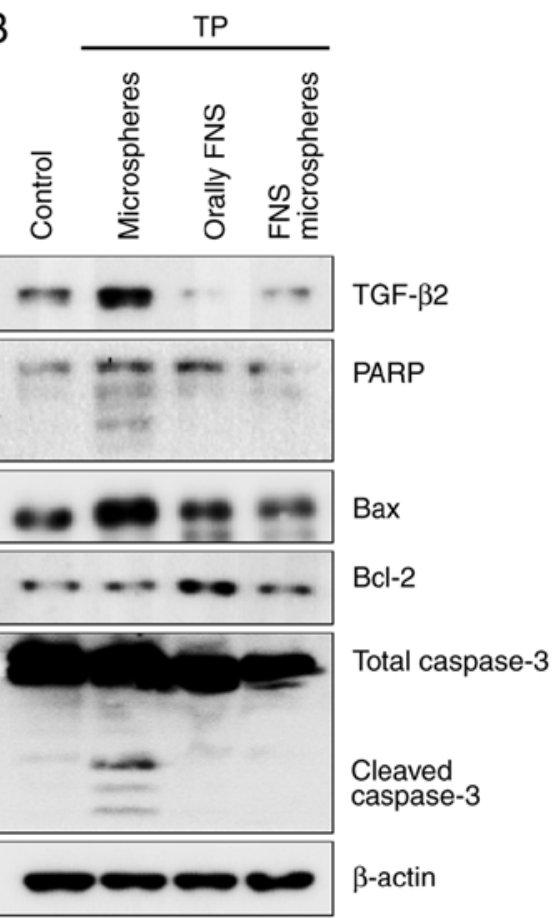

C

TP
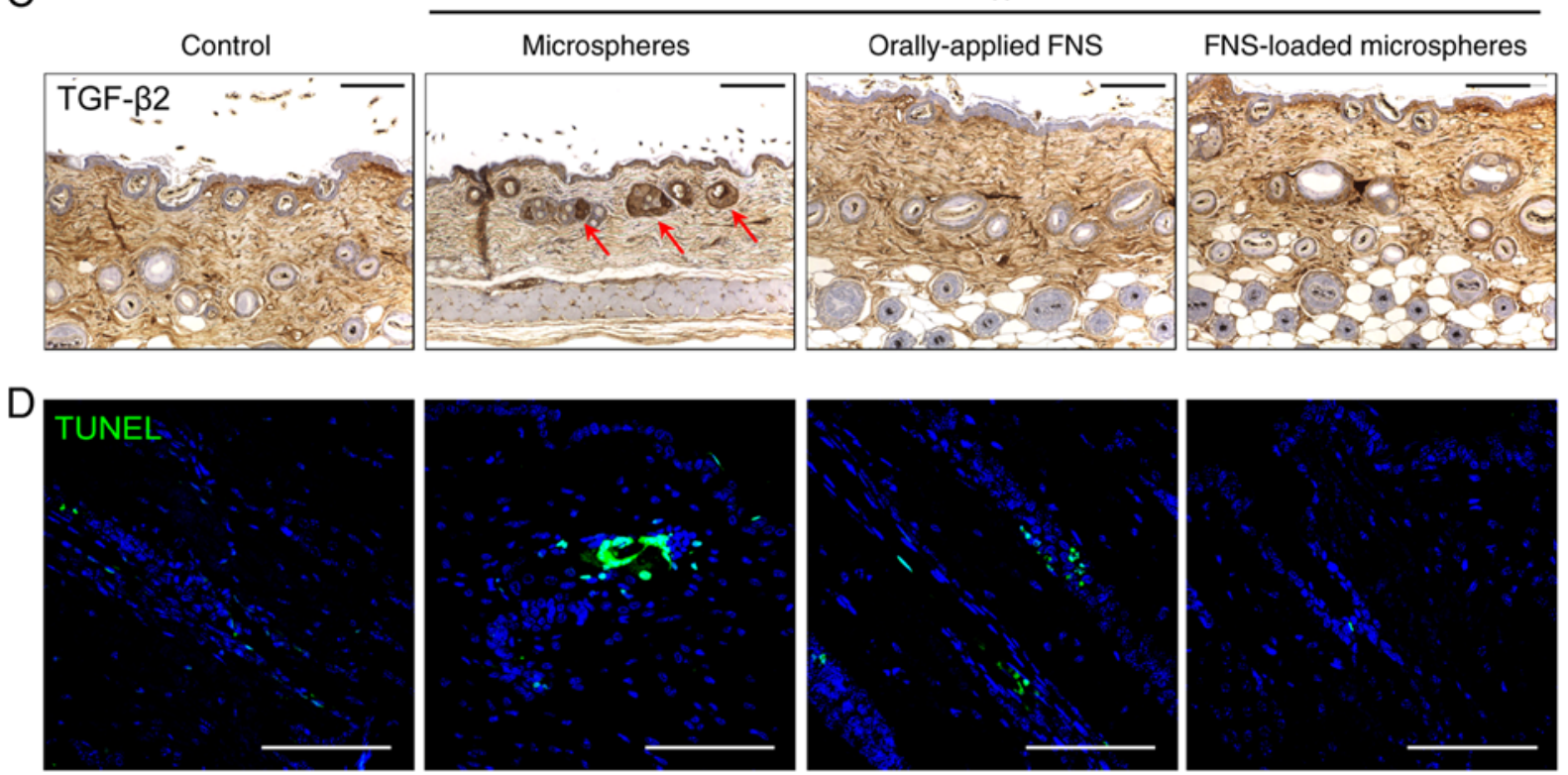

Figure 5. FNS-loaded microspheres hinder testosterone-induced apoptosis in mouse hair follicles. Mice were sacrificed and skin biopsies were obtained 9 weeks after the start of treatment. (A) Following treatment with testosterone and orally-applied FNS or FNS-loaded microspheres, $B c l-2, B a x$ and $T G F-\beta 2$ transcripts were detected via reverse-transcription-quantitative polymerase chain reaction analysis. (B) Dorsal skin lysates were immunoblotted using anti-TGF- $\beta 2$, anti-PARP, anti-Bcl-2, anti-Bax, anti-cleaved caspase-3 and anti- $\beta$-actin antibodies. (C) Comparison of histological images (TGF- $\beta 2$ indicated by red arrows). (D) Positive staining of damaged cell nucleus with TUNEL stain (green fluorescence). Scale bar, $100 \mu \mathrm{m}$. All data are presented as the mean \pm standard error of the mean from three independent experiments. " $\mathrm{P}<0.05$ and ${ }^{* *} \mathrm{P}<0.01$, vs. microspheres-treated group. TP, testosterone propionate; FNS, finasteride; TGF- $\beta 2$, transforming growth factor- $\beta 2$, PARP, poly (ADP ribose) polymerase; Bcl-2, B-cell lymphoma 2 ; Bax, Bcl-2-associated X-protein; TUNEL, terminal deoxynucleotidyl transferase dUTP nick end labeling.

leads hair follicles into the catagen phase, which leads to increased levels of TGF- $\beta 2$ and the apoptosis of hair follicle cells (26). The increase in TGF- $\beta 2$ alters the regulation of Bcl-2 and caspase-3, thereby affecting the apoptosis of hair cells. The expression of Bcl-2 in the finasteride-loaded microspheres-treated group was increased, whereas the expression levels of cleaved-PARP, cleaved-caspase-3, TGF- $\beta 2$ and Bax were lower than those in the microspheres-treated group (Fig. 5A and B). In addition, TGF- $\beta 2$ was expressed and TUNEL staining, which indicated DNA damage by apoptosis, was observed in the hair follicles of the testosterone-treated mice, in which the catagen and telogen phases were maintained. However, the expression of TGF- $\beta 2$ and TUNEL staining were reduced in the orally-applied finasteride-and finasteride-loaded microspheres-treated groups, in which hair follicle growth was induced in the anagen phase (Fig. 5C and D). These results 
suggest that a single injection of finasteride-loaded microspheres interferes with the expression of apoptotic factors in testosterone-exposed hair follicles.

\section{Discussion}

The present study was performed to investigate the effectiveness of one-off subcutaneous dosing of finasteride-loaded microspheres (finasteride:PLGA=1:4) on the inhibition of $5 \alpha$-reductase compared with that of repeated oral dosing of finasteride, and to evaluate the anagen entry time in a TP-induced AGA mouse model over 10 weeks. Hair shafts began to form in some mice at week 4 in the control group, and at week 6 in the orally-applied finasteride- and the subcutaneous finasteride-loaded microspheres-treated groups. The hair growth effects ( $5 \alpha$-reductase inhibitory effects) exerted by orally-applied finasteride- and finasteride-loaded microspheres were similar. In addition, serum DHT was significantly decreased in the orally-applied finasteride- and finasteride-loaded microspheres-treated groups compared with that in the microspheres-treated group, indicating similar $5 \alpha$-reductase inhibitory effects after 8 weeks. The activity of DHT is $\sim 10$ times more potent than that of testosterone, and suppresses hair growth by acting on the hair root (27). Androgen receptors are present only in DPCs, which are important in hair follicle formation, and not in hair follicular matrix cells derived from epidermal cells. DHT binds to DPCs and either inhibits the secretion of substances that stimulate hair follicular matrix growth or secretes substances that suppress hair growth (28).

Finasteride is widely used in AGA, which significantly improves hair growth and slows hair loss compared with placebo $(11,29)$. However, finasteride is not recommended for use in women due to the risk of birth defects in women of childbearing age and its high transdermal absorption. In men, the risk of developing sexual dysfunction and the inconvenience of long-term daily administration of oral finasteride have increased. The US Food and Drug Administration (FDA) announced a specific label change on April 11, 2012 to include libido, erectile, ejaculatory and orgasmic disorders as side effects for Propecia (finasteride $1 \mathrm{mg}$ ) and Proscar (finasteride $5 \mathrm{mg}$ ), which have been reported to continue following discontinuation of the drug (30). Studies have shown that sexual arousal occurs at a rate of $3.4-15.8 \%$, erectile dysfunction is the most common side effect, and ejaculatory disorder and decreased libido occur at the beginning of treatment $(10,11,31-34)$. These effects returned to normal on stopping or in time following continuous use of the drug $(10,32)$. Current evidence from finasteride indicates safety, although concerns regarding sexual side effects are increasing. Therefore, investigations on the development of a systemic delivery system in controlled release form with fewer adverse effects is important $(14,35,36)$. Dutasteride, as another therapeutic agent, is an inhibitor of type I and type II $5 \alpha$-reductase, whereas finasteride inhibits only the type II enzyme. Dutasteride is approximately three times and 100 times more potent than finasteride for type I and type II, respectively (37). However, $\sim 50 \%$ of participants treated with dutasteride for 48 weeks have reported one or more adverse effects, including nasopharyngitis and erectile dysfunction $(38,39)$. Furthermore, studies involving 6,460 patients concluded that dutasteride was effective for improving benign prostate hyperplasia, but was associated with an increased risk of sexual dysfunction $(40,41)$. In addition, dutasteride has been demonstrated to be effective in several trials in AGA, but it is not approved by the US FDA for AGA due to possible adverse effects, including reduced sperm count, gynecomastia and drug-drug interactions (42).

A single dose of finasteride-loaded microspheres effectively alleviated hair loss for $>4$ weeks, and its effectiveness for up to 8 weeks was confirmed. The total 30-day dose administered was based on orally-applied finasteride dosage, and it was suggested that the effects of a lower dose administered over a longer period may be similar to those of orally-applied finasteride daily for 8 weeks. Furthermore, a single injection can reduce the inconvenience of daily administration and the requirement for drug storage.

In conclusion, the present study demonstrated the inhibitory effect of finasteride-loaded microspheres on $5 \alpha$-reductase. Finasteride-loaded microspheres improved testosterone-induced hair loss, and its effect in a single dose on hair follicle tissue growth was similar to that of daily orally-applied finasteride for up to 8 weeks. This suggests that the effect of finasteride-loaded microspheres does not appear immediately following administration, but rather that there is a delayed onset of drug efficacy following the initial dosing. The present study showed that the growth period, length and number of hairs following orally-applied finasterideand finasteride-loaded microspheres administration were similar, although the injection dose was lower. Therefore, the evaluation of a novel dosage form demonstrated the possibility of an effective novel dose and administration route for finasteride. However, the present study included only a short-term experiment and did not investigate the intra-body distribution of finasteride-loaded microspheres. Therefore, long-term studies in mice are required for the acceptance of dosage and periodicity of injections in the scalp, followed by long-term experiments assessing the distribution and permanence of finasteride-loaded microspheres by injection in further investigations.

\section{Acknowledgements}

Not applicable.

\section{Funding}

The present study was supported by Inventage Lab, Inc. (Seongnam, Korea; grant no. 20171134).

\section{Availability of data and materials}

The analyzed datasets generated during the present study are available from the corresponding author on reasonable request.

\section{Authors' contributions}

HSL, BJK, JHK and JN designed experiments; JHK, JN, DHB, BCL, EL, MJC, CHR, and SL performed experiments; HSL, BJK, JHK, JN, CHR, SL, SKM and BCP analyzed and interpreted data; JHK, JN and DHB prepared figures; HSL, 
BJK, JHK and JN wrote the manuscript. HSL and BJK had primary responsibility for final content. All authors have read and approved the final manuscript.

\section{Ethics approval and consent to participate}

The present study was approved by the Institutional Animal Care and Use Committee of Chung-Ang University (2018-00078).

\section{Patient consent for publication}

Not applicable.

\section{Competing interests}

The authors confirm that they have no competing interests.

\section{References}

1. Sinclair R: Male pattern androgenetic alopecia. BMJ 317 865-869, 1998.

2. Cash TF: The psychology of hair loss and its implications for patient care. Clin Dermatol 19: 161-166, 2001.

3. Whiting DA: Possible mechanisms of miniaturization during androgenetic alopecia or pattern hair loss. J Am Acad Dermatol 45 (Suppl 3): S81-S86, 2001.

4. Urysiak-Czubatka I, Kmieć ML and Broniarczyk-Dyła G: Assessment of the usefulness of dihydrotestosterone in the diagnostics of patients with androgenetic alopecia. Postepy Dermatol Alergol 31: 207-215, 2014.

5. Aggarwal S, Thareja S, Verma A, Bhardwaj TR and Kumar M: An overview on 5alpha-reductase inhibitors. Steroids 75 $109-153,2010$

6. Azzouni F, Godoy A, Li Y and Mohler J: The 5 alpha-reductase isozyme family: A review of basic biology and their role in human diseases. Adv Urol 2012: 530121, 2012.

7. McConnell JD, Wilson JD, George FW, Geller J, Pappas F and Stoner E: Finasteride, an inhibitor of 5 alpha-reductase suppresses prostatic dihydrotestosterone in men with benign prostatic hyperplasia. J Clin Endocrinol Metab 74: 505-508, 1992.

8. Gormley GJ, Stoner E, Bruskewitz RC, Imperato-McGinley J, Walsh PC, McConnell JD, Andriole GL, Geller J, Bracken BR, Tenover JS, et al: The effect of finasteride in men with benign prostatic hyperplasia. The Finasteride Study Group. N Engl J Med 327: 1185-1191, 1992.

9. Drake L, Hordinsky M, Fiedler V, Swinehart J, Unger WP, Cotterill PC, Thiboutot DM, Lowe N, Jacobson C, Whiting D, et al: The effects of finasteride on scalp skin and serum androgen levels in men with androgenetic alopecia. J Am Acad Dermatol 41: 550-554, 1999.

10. Kaufman KD, Olsen EA, Whiting D, Savin R, DeVillez R, Bergfeld W, Price VH, Van Neste D, Roberts JL, Hordinsky M, et al: Finasteride in the treatment of men with androgenetic alopecia. Finasteride Male Pattern Hair Loss Study Group. J Am Acad Dermatol 39: 578-589, 1998.

11. Finasteride Male Pattern Hair Loss Study Group: Long-term (5-year) multinational experience with finasteride $1 \mathrm{mg}$ in the treatment of men with androgenetic alopecia. Eur J Dermatol 12: 38-49, 2002

12. Whiting DA, Olsen EA, Savin R, Halper L, Rodgers A, Wang L, Hustad C and Palmisano J; Male Pattern HairLoss Study Group: Efficacy and tolerability of finasteride $1 \mathrm{mg}$ in men aged 41 to 60 years with male pattern hair loss. Eur J Dermatol 13 150-160, 2003.

13. Mella JM, Perret MC, Manzotti M, Catalano HN and Guyatt G: Efficacy and safety of finasteride therapy for androgenetic alopecia: A systematic review. Arch Dermatol 146: 1141-1150, 2010.

14. Peng D, Huang K, Liu Y and Liu S: Preparation of novel polymeric microspheres for controlled release of finasteride. Int J Pharm 342: 82-86, 2007.
15. Caon T, Porto LC, Granada A, Tagliari MP, Silva MA, Simões CM, Borsali R and Soldi V: Chitosan-decorated polystyrene-b-poly(acrylic acid) polymersomes as novel carriers for topical delivery of finasteride. Eur J Pharm Sci 52: 165-172, 2014.

16. Freiberg $S$ and Zhu X: Polymer microspheres for controlled drug release. Int J Pharm 282: 1-18, 2004.

17. Nojehdehian $\mathrm{H}$ and Ekrami M: Loading of gentamicin sulfate into poly (lactic-co-glycolic acid) biodegradable microspheres. Shahid Beheshti University. J Dent Sch 33: 145-151, 2015.

18. Sinha V, Bansal K, Kaushik R, Kumria R and Trehan A: Poly- $\epsilon$-caprolactone microspheres and nanospheres: An overview. Int J Pharma 278: 1-23, 2004.

19. Burns SA, Hard R, Hicks WL Jr, Bright FV, Cohan D, Sigurdson L and Gardella JA Jr: Determining the protein drug release characteristics and cell adhesion to a PLLA or PLGA biodegradable polymer membrane. J Biomed Mater Res A 94: 27-37, 2010.

20. Danhier F, Ansorena E, Silva JM, Coco R, Le Breton A and Préat V: PLGA-based nanoparticles: An overview of biomedical applications. J Control Release 161: 505-522, 2012.

21. Corrigan OI and $\mathrm{Li} \mathrm{X}$ : Quantifying drug release from PLGA nanoparticulates. Eur J Pharm Sci 37: 477-485, 2009.

22. Mu L and Feng S: A novel controlled release formulation for the anticancer drug paclitaxel (Taxol): PLGA nanoparticles containing vitamin E TPGS. J Control Release 86: 33-48, 2003.

23. Wang ZD, Feng Y, Ma LY, Li X, Ding WF and Chen XM: Hair growth promoting effect of white wax and policosanol from white wax on the mouse model of testosterone-induced hair loss. Biomed Pharmacother 89: 438-446, 2017.

24. Livak KJ and Schmittgen TD: Analysis of relative gene expression data using real-time quantitative PCR and the 2(-Delta Delta C(T)) method. Methods 25: 402-408, 2001.

25. Kim YJ, Choi MJ, Bak DH, Lee BC, Ko EJ, Ahn GR, Ahn SW, Kim MJ, Na J and Kim BJ: Topical administration of EGF suppresses immune response and protects skin barrier in DNCB-induced atopic dermatitis in NC/Nga mice. Sci Rep 8: 11895, 2018.

26. Hibino T and Nishiyama T: Role of TGF-beta2 in the human hair cycle. J Dermatol Sci 35: 9-18, 2004.

27. Chen W, Zouboulis CC and Orfanos CE: The 5-alpha reductase system and its inhibitors. Recent development and its perspective in treating androgen-dependent skin disorders. Dermatology 193: 177-184, 1996.

28. Thornton MJ, Messenger AG, Elliott K and Randall VA: Effect of androgens on the growth of cultured human dermal papilla cells derived from beard and scalp hair follicles. J Invest Dermatol 97: 345-348, 1991.

29. Sato A and Takeda A: Evaluation of efficacy and safety of finasteride $1 \mathrm{mg}$ in 3,177 Japanese men with androgenetic alopecia. J Dermatol 39: 27-32, 2012

30. Mysore V and Shashikumar B: Guidelines on the use of finasteride in androgenetic alopecia. Indian J Dermatol Venereol Leprol 82: 128-134, 2016.

31. Hirshburg JM, Kelsey PA, Therrien CA, Gavino AC and Reichenberg JS: Adverse effects and safety of 5-alpha reductase inhibitors (finasteride, dutasteride): A systematic review. J Clin Aesthet Dermatol 9: 56-62, 2016.

32. Wessells H, Roy J, Bannow J, Grayhack J, Matsumoto AM, Tenover L, Herlihy R, Fitch W, Labasky R, Auerbach S, et al: Incidence and severity of sexual adverse experiences in finasteride and placebo-treated men with benign prostatic hyperplasia. Urology 61: 579-584, 2003.

33. Moinpour CM, Darke AK, Donaldson GW, Thompson IM Jr, Langley C, Ankerst DP, Patrick DL, Ware JE Jr, Ganz PA, Shumaker SA, et al: Longitudinal analysis of sexual function reported by men in the prostate cancer prevention trial. J Natl Cancer Inst 99: 1025-1035, 2007.

34. Carbone D Jr and Hodges S: Medical therapy for benign prostatic hyperplasia: Sexual dysfunction and impact on quality of life. Int J Impot Res 15: 299-306, 2003.

35. Peng D, Huang K, Liu Y, Liu S, Wu H and Xiao H: Preparation of carbon dioxide/propylene oxide/ع-caprolactone copolymers and their drug release behaviors. Polymer Bull 59: 117-125, 2007.

36. Ahmed OA, Hussein AK and Mady FM: Optimisation of microstructured biodegradable finasteride formulation for depot parenteral application. J Microencapsul 33: 229-238, 2016.

37. Clark RV, Hermann DJ, Cunningham GR, Wilson TH, Morrill BB and Hobbs S: Marked suppression of dihydrotestosterone in men with benign prostatic hyperplasia by dutasteride, a dual 5 $\alpha$-reductase inhibitor. J Clin Endocrinol Metab 89: 2179-2184, 2004. 
38. Tsai TF, Choi GS, Kim BJ, Kim MB, Ng CF, Kochhar P, Jasper S, Brotherton B, Orban B and Lulic Z: Prospective randomized study of sexual function in men taking dutasteride for the treatment of androgenetic alopecia. J Dermatol 45: 799-804, 2018.

39. Fertig R, Shapiro J, Bergfeld W and Tosti A: Investigation of the plausibility of 5-alpha-reductase inhibitor syndrome. Skin Appendage Disord 2: 120-129, 2017.

40. Wilt TJ, MacDonald R, Hagerty K, Schellhammer P, Tacklind J, Somerfield MR and Kramer BS: 5- $\alpha$-reductase inhibitors for prostate cancer chemoprevention: An updated Cochrane systematic review. BJU Int 106: 1444-1451, 2010.
41. Wu XJ, Zhi Y, Zheng J, He P, Zhou XZ, Li WB and Zhou ZS: Dutasteride on benign prostatic hyperplasia: A meta-analysis on randomized clinical trials in 6,460 patients. Urology 83: 539-543, 2014.

42. Arif T, Dorjay K, Adil M and Sami M: Dutasteride in androgenetic alopecia: An update. Curr Clin Pharmacol 12: 31-35, 2017.

This work is licensed under a Creative Commons Attribution-NonCommercial-NoDerivatives 4.0 International (CC BY-NC-ND 4.0) License. 